\title{
Binding of circulating anti-MUC1 antibody and serum MUC1 antigen in stage IV breast cancer
}

\author{
YAN TANG $^{1 *}$, XIUXIA CUI ${ }^{2 *}$, HAN XIAO $^{1}$, SHENGKUN QI $^{3}$, XIAOPING HU ${ }^{4}$, QIONG YU $^{1}$, \\ GUANG SHI ${ }^{1}$, XUE ZHANG ${ }^{1}$, JIAYING GU ${ }^{1}$, YONGLI YU ${ }^{3}$, LIYING WANG ${ }^{4}$ and YARONG LI $^{1}$ \\ ${ }^{1}$ Department of Oncology, The Second Hospital, Jilin University, Changchun, Jilin 130041; \\ ${ }^{2}$ Department of Teaching and Scientific Research, The First Affiliated Hospital of Zhengzhou University, Zhengzhou, \\ Henan 450052; Departments of ${ }^{3}$ Immunology and ${ }^{4}$ Molecular Biology, \\ Norman Bethune Medical College, Jilin University, Changchun, Jilin 130021, P.R. China
}

Received November 25, 2015; Accepted November 21, 2016

DOI: $10.3892 / \mathrm{mmr} .2017 .6323$

\begin{abstract}
The present study aimed to investigate the binding of circulating mucin 1 (MUC1) antibody with serum MUC1 antigen in stage IV breast cancer. Serum samples of 61 patients with stage IV breast cancer and 64 patients with early-stage breast cancer were collected. The anti-MUC1 antibody (IgG) and MUC1 antigen (cancer antigen 15-3; Ca15-3) were detected using an indirect enzyme-linked immunosorbent assay (I-ELISA) and ELISA, respectively. The MUC1 IgG affinity was detected using a urea degradation combining ELISA. Western blot analysis and an inhibition test were performed for verification of the binding of anti-MUC1 IgG with MUC1 antigen, and their correlation was analyzed. The results showed that there was a negative correlation between anti-MUC1 IgG and CA15-3 antigen in stage IV breast cancer when positive CA15-3 antigen and/or anti-MUC1 IgG were selected ( $\mathrm{r}=-0.417 ; \mathrm{P}=0.0044)$. The positive anti-MUC1 IgG with positive Ca15-3 antigen was more common in stage IV breast cancer, compared with early-stage breast cancer $\left(\chi^{2}=4.629 ; \mathrm{P}=0.031\right)$, however, Ca15-3 antigen positivity was higher in stage IV breast cancer, compared with early-stage breast cancer $\left(\chi^{2}=10.58 ; P=0.001\right)$. Anti-MUC1 $\operatorname{IgG}$ was able to bind to the MUC1 antigen in stage IV breast cancer. No differences in the 8R-MUCPT inhibition ratio were found between the two groups $(\mathrm{P}=0.778)$, and there were no differences in the affinity of anti-MUC1 IgG $(\mathrm{P}=0.873)$. In stage IV
\end{abstract}

Correspondence to: Dr Yarong Li, Department of Oncology, The Second Hospital, Jilin University, 218 Ziqiang Street, Changchun, Jilin 130041, P.R. China

E-mail: doctor.lyr@163.com

Dr Liying Wang, Department of Molecular Biology, Norman Bethune Medical College, Jilin University, 828 Xinmin Street, Changchun, Jilin 130021, P.R. China

E-mail: wlying@mail.jlu.edu.cn

${ }^{*}$ Contributed equally

Key words: mucin 1, antibody, antigen, breast cancer, binding breast cancer, circulating anti-MUC1 antibody was found to bind serum MUC1 antigen, although their compatibility was low. No significant difference was found in the affinity of the anti-MUC1 antibody between stage IV breast cancer and early-stage breast cancer.

\section{Introduction}

Cell surface-associated mucin 1 (MUC1) is a transmembrane protein consisting of an extracellular domain containing 20-125 tandem repeat arrays, followed by a transmembrane domain and a short cytoplasmic tail. MUC1 is overexpressed and aberrantly glycosylated in carcinoma, including $90 \%$ of breast cancer cases $(1,2)$. Its broad distribution on primary tumors and metastasis renders it an attractive vaccine target $(3,4)$. Studies have suggested that antibodies targeting the MUC1-N-terminal domain may be instrumental in preventing metastasis, counteracting immune suppression and effecting antibody-dependent cell-mediated cytotoxicity $(5,6)$. The association between elevated levels of anti-MUC1 antibody and improved survival rates has been observed in patients with early-stage breast cancer and other types of cancer $(6,7)$. The initial evaluation of MUC1 peptide/glycopeptides has found them to be immunogenic and safe, however, their antitumor responses are limited (8). Adjuvant vaccination with MUC1 glycopeptide polyvalent vaccines, which induce a marked humoral response, may prevent the recurrence of disease in patients with early breast cancer, which suggests MUC1 immunotherapy is beneficial (9). Immunotherapy, which relies on humoral responses to achieve its clinical effect, is most effective in patients with a low tumor burden (minimal residual disease) (10). The marked immune response and immunologic memory, which are associated with active immunotherapy, administered in an adjuvant setting, enable constant surveillance to protect patients with cancer from recurrence of disease, although it is of limited use in advanced metastatic disease. However, the internalization of anti-MUC1 antibodies by tumor cells provides a route for the development of therapeutics based on this antibody $(11,12)$. This allows for other therapeutic approaches, including the delivery of toxic compounds into tumor cells, for example, antibody drug conjugates or immunotoxins $(13,14)$. 
In our previous study (15), circulating anti-MUC1 antibody ( $\operatorname{IgG})$ was detected using an indirect enzyme-linked immunosorbent assay (I-ELISA) with a recombinant MUC1 protein containing six tandem repeat sequences of MUC1. A significant negative correlation was found between the serum levels of MUC1 antigen (cancer antigen 15-3; CA15-3) and that of anti-MUC1 antibody in patients with malignant tumors at advanced stages. According to this result, the present study hypothesized that circulating anti-MUC1 antibodies were able to bind to MUC1 dispersed into the blood in stage IV breast cancer. To clarify the binding of serum anti-MUC1 antibody to the MUC1 antigen in stage IV breast cancer, the present study analyzed serum samples collected from 61 patients with stage IV breast cancer and 64 patients with early-stage breast cancer, and performed comparative analysis between stage IV and early-stage breast cancer.

\section{Materials and methods}

Specimens. Between January 2012 and February 2014, 61 serum samples were obtained from 61 patients with newly diagnosed stage IV breast cancer (31-67 years old; median 43 years) at the Second Hospital of Jilin University (Changchun, China). In addition, 64 serum samples were obtained from 64 patients with early-stage breast cancer (stages I, II and III; 35-65 years old; median 45 years) at the same hospital. Venous blood samples $(5 \mathrm{ml})$ were collected from patients and centrifuged at $225 \mathrm{xg}$ and $-4^{\circ} \mathrm{C}$ for $10 \mathrm{~min}$. Subsequently, serum was separated immediately following centrifugation and stored at $-40{ }^{\circ} \mathrm{C}$ until analysis. All patients included were post-primary treatment. The 61 patients with stage IV breast cancer included 51 with infiltrating duct carcinoma, 4 with medullary carcinoma and 6 with carcinoma simplex. All cases were cases of recurrent disease, including 24 with regional lymph node recurrence combined with distant metastasis and 37 with distant metastasis only. The distant metastasis involved one or several locations. Patients with distant metastasis included 16 with hepatic metastasis, 30 with pulmonary metastasis, 30 with osseous metastasis, 4 with brain metastasis, 14 with distant lymph node metastasis (supraclavicular nodes of opposite side or lymph nodes of neck), 10 with pleural metastasis and 12 with peritoneal metastasis. The 64 patients with early-stage breast cancer consisted of 57 with infiltrating duct carcinoma, 3 with medullary carcinoma and 4 with carcinoma simplex; the disease staging was as follows: Stage I $(n=10)$; stage II $(n=38)$; and stage III $(n=16)$. The clinical stages of breast cancer were according to the 7th edition of the American Joint Committee on Cancer staging system (15). The study was approved by the Ethical Committee of Jilin University. Written informed consent was obtained from patients or their families.

Preparation of recombinant protein. The recombinant 8R-MUCPT protein was prepared according to a previously reported method (16). Briefly, a cDNA fragment, obtained by polymerase chain reaction, containing the human MUC1 variable number of tandem repeats (VNTR) encoding sequence with six tandem repeats was subcloned into the prokaryotic expression vector pET26b plasmid, in which there was an eight-arginine-encoding sequence at the $\mathrm{N}$-terminal insertion end. Subsequently, the pET26b-8R-MUCPT plasmid was directly transformed into the BL21 Escherichia coli (Beijing Dingguo Inc., Beijing, China) bacterial strain and individual clones were grown in Luria-Bertani liquid medium with $4 \mu \mathrm{g} / \mathrm{ml}$ of chloramphenicol. Purification of the recombinant protein with a polyhistidine-tail at the C-terminal insertion end was performed using $\mathrm{Ni}$-chromate affinity chromatography. Another recombinant protein, $3 \mathrm{aB}$, encoding 224 amino acids was used for the ELISA inhibition test, which was also constructed in Department of Molecular Biology, Institute of Basic Medical Sciences, Jilin University.

Detection of anti-MUC1 IgG with 8R-MUCPT using I-ELISA. The serum anti-MUC1 IgG was detected using I-ELISA (16). The 8R-MUCPT fusion protein corresponding to the six VNTR region of the MUC1 protein core was used as a catcher and coated onto the 96-well flat-bottom plates. Individual results were calculated as the mean optical density (OD) of two repeat sample wells; the cut-off value was 1.30 , which was defined as an anti-MUC1 IgG level equal to or higher than the mean OD value of the total breast cancer samples.

Detection of MUC1 antigen using ELISA. The CA15-3 antigen is defined as a glycoprotein, which binds to two monoclonal antibodies, namely, DF3 and 115D8. The DF3 antibody recognizes the VNTR of MUC1 (sequence DTRPAPGS), and the 115D8 monoclonal antibody is the solid-phase capture antibody, which binds to a peptide-carbohydrate epitope on the same repeat (17). In the present study, CA15-3 was measured using an ELISA kit (R\&D Systems, Inc., Minneapolis, MN, USA), and all steps were performed according to the manufacturer's protocols. Briefly, $100 \mu \mathrm{l}$ of the patient sample, control and calibrator were dispensed in ligand-coated tubes. Following the addition of $100 \mu \mathrm{l}$ ligand-labeled monoclonal antibody (mAb), the tubes were incubated at $37^{\circ} \mathrm{C}$ for $1 \mathrm{~h}$. Subsequently, $100 \mu \mathrm{l}$ anti-ligand $\mathrm{mAb}$ was added, followed by incubation for $1 \mathrm{~h}$. The OD values were determined at $450 \mathrm{~nm}$ in an ELISA autoreader (Labsystems Diagnostics Ltd., Vantaa, Finland). The cut-off value was $36.0 \mathrm{U} / \mathrm{ml}$.

Western blot analysis and inhibition test with MUC1 VNTR antigen. According to the previously reported method (18), purified recombinant $8 \mathrm{R}-\mathrm{MUCPT}$ protein $(10 \mu \mathrm{g})$ was resolved by $10 \%$ sodium dodecyl sulfate-polyacrylamide gel electrophoresis, and then transferred onto a nitrocellulose membrane (Advantec MFS, Inc., Dubulin, CA, USA). The membranes were sectioned vertically into 4 sections of the same size and were incubated in 5\% milk/PBS (Sigma-Aldrich; Merck Millipore, Darmstadt, Germany) at $4^{\circ} \mathrm{C}$ overnight. The following day, the membranes were preincubated with either mouse anti-human MUC1 VNTR mAb (BD Pharmingen, Inc., San Diego, CA, USA) in a 1:50 dilution or mouse anti-human monoclonal anti-hepatitis B surface antigen antibody (Bioson Corporation, Beijing, China) in a 1:20 dilution at room temperature for $3 \mathrm{~h}$. Following washing with PBS, the membranes were incubated with serum positive for the anti-MUC1 antibody, derived from an MUC1-positive patient with stage IV breast cancer, in a $1: 5$ dilution at $4^{\circ} \mathrm{C}$ overnight, 
and then washed and incubated with peroxidase-conjugated goat anti-human IgG (Bioson Corporation) in a 1:200 dilution with $5 \%$ milk/PBS at $25^{\circ} \mathrm{C}$ for $1 \mathrm{~h}$. Following washing, 3.3'-diaminobenzidine was added to the membranes for the coloration reaction.

ELISA inhibition test with MUC1 VNTR antigen. Each serum sample was incubated, respectively, with 8R-MUCPT, $3 \mathrm{aB}$, poly-arginine (poly-R, Sigma-Aldrich; Merck Millipore) or poly-histidine (poly-H, Sigma-Aldrich; Merck Millipore) at the same molar concentration of $8 \mathrm{mM}$, followed by the detection of anti-MUC1 antibodies using I-ELISA with 8R-MUCPT as a coating antigen. All samples were measured in duplicate. The inhibition ratio of $8 \mathrm{R}-\mathrm{MUCPT}$ in the binding reaction of anti-MUC1 IgG and MUC1 antigen was calculated as follows: Inhibition ratio $(\%)=(\mathrm{OD}$ value of serum sample incubated with 8R-MUCPT-OD value of control serum or serum sample incubated without an inhibitor) x100 / OD value of control serum.

Detection of MUC1 IgG affinity by urea degradation combining ELISA.8R-MUCPT protein $(10 \mu \mathrm{g} / \mathrm{ml})$ in $0.05 \mathrm{~mol} / \mathrm{l}$ carbonate buffer ( $\mathrm{pH}$ 9.6) was coated onto 96-well flat-bottom plates at $4^{\circ} \mathrm{C}$ for $17 \mathrm{~h}$. The plates were washed with PBS three times, blocked with $5 \%$ milk/PBS at $37^{\circ} \mathrm{C}$ for $2 \mathrm{~h}$, and then incubated with sera from the patients in a 1:40 dilution with $10 \% \mathrm{milk} / \mathrm{PBS}$ at room temperature for $30 \mathrm{~min}$. Following washing twice with $0.05 \%$ Tween-20/PBS (Sigma-Aldrich; Merck Millipore), two plate wells were incubated with $8 \mathrm{~mol} / \mathrm{l}$ urea solution (Sigma-Aldrich; Merck Millipore) and another two wells with PBS at room temperature for $10 \mathrm{~min}$. The plates were washed three times with $0.05 \%$ Tween-20/PBS, and incubated with peroxidase-conjugated goat anti-human IgG in a 1: 250 dilution with 5\% milk/PBS at room temperature for $1 \mathrm{~h}$. The reaction was terminated by adding $O$-phenylenediamine dihydrochloride following washing three times with $0.05 \%$ Tween-20/PBS. The OD value was determined at A492 in an ELISA autoreader (Labsystems Diagnostics Ltd., Vantaa, Finland). All samples were measured in four wells. The avidity index (AI) was calculated as follows: $A I=(O D$ with urea / OD without urea) x100.

Statistical analysis. Statistical analysis was performed using SPSS 17.0 software (SPSS, Inc., Chicago, IL, USA). The percentages among the different groups were compared using the $\chi^{2}$ test. Differences between clinical stages were analyzed using a Kruskal-Wallis test. Correlations between two experimental groups were evaluated using linear regression analysis. An unpaired two-sample $t$-test was used to compare between values of two groups. $\mathrm{P}<0.05$ determined in the two-tailed test was considered to indicate a statistically significant difference.

\section{Results}

I-ELISA results of circulating anti-MUC1 IgG and Ca15-3 antigen. As shown in Table I, the serum level and positive rate of anti-MUC1 IgG were marginally elevated in patients with stage II breast cancer, compared with those with stage I breast cancer, but were marginally decreased in stage III breast cancer. Elevated levels were found in the stage IV patients. The patients with stages II, III and IV breast cancer showed a gradual increase in the level of Ca15-3 antigen and rate of positivity, compared with those with stage I disease. The OD value and positivity of anti-MUC1 IgG in the patients with stage IV cancer with regional lymph node recurrence and distant metastasis were marginally higher, compared with those in patients with distant metastasis only. By contrast, the serum level and positivity of Ca15-3 in patients with regional lymph node recurrence with distant metastasis were decreased, compared with those in patients with distant metastasis only, however, no statistically significant correlations were found among the groups $(\mathrm{P}>0.05)$.

Association between circulating anti-MUC1 IgG and the Cal5-3 antigen in stage IV breast cancer. No significant correlation was found between the level of circulating anti-MUC1 IgG and serum expression of CA15-3 in patients with stage IV breast cancer. However, a significant negative correlation was observed when positive serum level of CA15-3 antigen and/or anti-MUC1 IgG were selected ( $r=-0.417 ; \mathrm{P}=0.0044 ;$ Fig. 1 ), which suggested the formation of an MUC1 circulating immune complex (MUC1-CIC) or the binding of anti-MUC1 IgG with CA15-3 antigen in stage IV breast cancer. The same was observed in stage II breast cancer, in which there was a negative correlation when positive CA15-3 antigen and/or anti-MUC1 IgG were selected ( $\mathrm{r}=-0.630 ; \mathrm{P}=0.0029$; Fig. 1). For stages I and III, no significant correlations were found due to fewer samples. However, if all positive serum levels of CA15-3 antigen and/or anti-MUC1 IgG were selected between stages I and III, omitting stage IV, a negative correlation was observed $(r=-0.605$; $\mathrm{P}<0.001$; Fig. 1).

As presented in Fig. 1, for each stage of breast cancer, the OD value of the serum sample was divided into four groups (I, II, III and IV) by cut-off lines. In group I, positive anti-MUC1 IgG was detected together with negative CA15-3 antigen. Negative anti-MUC1 IgG and negative CA15-3 antigen was present in group II. In group III, negative anti-MUC1 IgG and positive CA15-3 antigen were found. In group IV, positive anti-MUC1 IgG and positive CA15-3 were shown. In the stage IV cancer samples, an increased number (8/61) were in group IV, compared with samples in other stages of disease $\left(1 / 64 ; \chi^{2}=4.629 ; P=0.031\right)$. Fewer samples were positive for CA15-3 (12/64) in early-stage breast cancer, compared with stage IV breast cancer $\left(28 / 61 ; \chi^{2}=10.58 ; \mathrm{P}=0.0011\right)$. The above results suggested that circulating anti-MUC1 antibody was able to bind serum MUC1 antigen and form MUC1-CIC in stage IV and early-stage breast cancer, however, the compatibility of anti-MUC1 IgG and MUC1 antigen in stage IV breast cancer may have been lower.

Western blot analysis and inhibition test with the MUC1 VNTR antigen. The results of the western blot analysis and inhibition test showed that 8R-MUCPT was recognized by natural anti-MUC1 antibody in the serum, and this was inhibited by anti-MUC1 VNTR mAb when at a sufficient quantity to neutralize the VNTR region on 8R-MUCPT (Fig. 2). This demonstrated that circulating anti-MUC1 antibody was able to bind to the MUC1 antigen in stage IV breast cancer. 
Table I. Expression of anti-MUC1 IgG and Ca15-3 antigen in serum samples of patients with breast cancer.

\begin{tabular}{lccc}
\hline & & \multicolumn{2}{c}{ Optical density (positive rate, \%) } \\
\cline { 3 - 4 } Stage & $\mathrm{n}$ & Anti-MUC1 IgG & Ca15-3 antigen \\
\hline I & 10 & $1.32 \pm 0.18(30.00)$ & $20.35 \pm 1.29(10.00)$ \\
II & 38 & $1.33 \pm 0.24(36.84)$ & $24.34 \pm 7.98(15.79)$ \\
III & 16 & $1.14 \pm 0.24(18.75)$ & $30.79 \pm 7.06(31.25)$ \\
IV & 61 & $1.32 \pm 0.38(44.26)$ & $32.80 \pm 8.50(45.90)$ \\
Regional lymph node recurrence & 24 & $1.40 \pm 0.26(50.00)$ & $33.05 \pm 7.92(41.67)$ \\
with distant metastasis & & & \\
Distant metastasis only & 37 & $1.27 \pm 0.32(40.54)$ & $28.97 \pm 8.96(48.65)$ \\
Total & 125 & $1.30 \pm 0.27(37.60)$ &
\end{tabular}

MUC1, mucin 1; Ca15-3, cancer antigen 15-3.
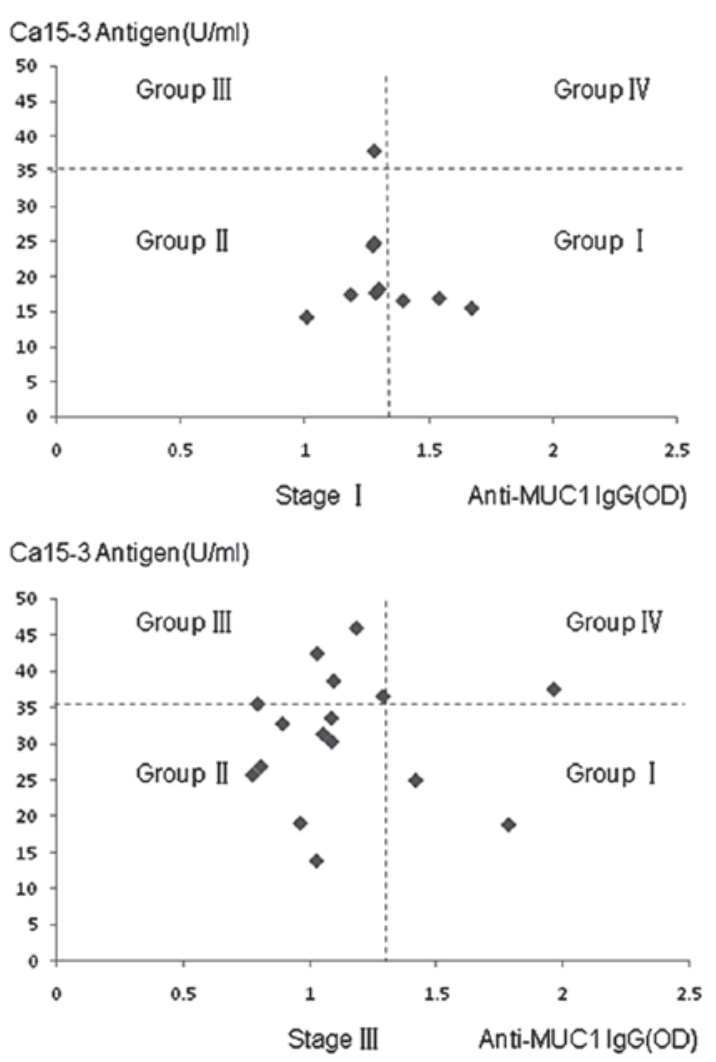

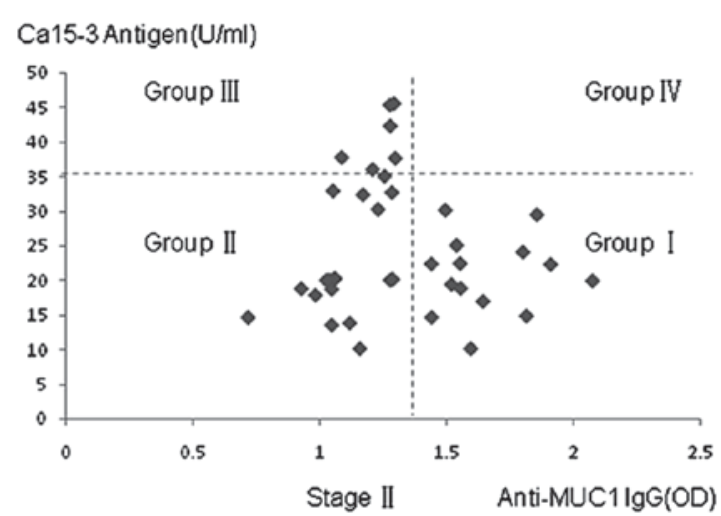

Ca15-3 Antigen(U/ml)

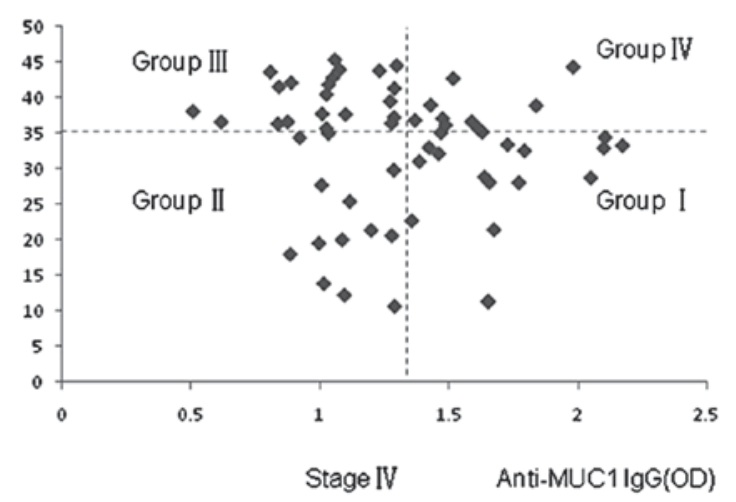

Figure 1. Levels of anti-MUC1 IgG and Ca15-3 antigen in different stages of breast cancer. The dotted lines indicate the cutoff values. The cut-off value of anti-MUC1 IgG was 1.30 (OD value) and that of Ca15-3 antigen was $36.0 \mathrm{U} / \mathrm{ml}$. MUC1, mucin 1; Ca15-3, cancer antigen 15-3; OD, optical density.

ELISA inhibition test with the MUC1 VNTR antigen. The results of the ELISA inhibition test showed that 8R-MUCPT efficiently neutralized the natural anti-MUC1 antibody in the serum, whereas the recombinant proteins $3 \mathrm{aB}$, poly- $\mathrm{R}$ and poly-H did not have this effect. This result confirmed that the MUC1 antigen or tandem repeat sequence of MUC1 reacted with anti-MUC1 antibody in the sera of patients with stage IV and early-stage breast cancer (Fig. 3).

A total of 11 serum samples from IV stage breast cancer and 11 samples from early-stage breast cancer were assessed in the inhibition test. The inhibition ratios of 8R-MUCPT in the binding of anti-MUC1 IgG and the MUC1 antigen were all $>45 \%$, with no statistically significant difference in the between the two groups ( $t$-test, $\mathrm{P}=0.778$ ). This result suggested that there was no significant difference in the affinity of MUC1-IgG between serum samples from stage IV and early-stage IV breast cancer, as MUC1-IgG affinity affects the inhibition ratio of 8R-MUCPT in the binding reaction in the assay.

Detection of the affinity of MUC1 IgG by urea degradation combining ELISA. The results of the urea degradation 


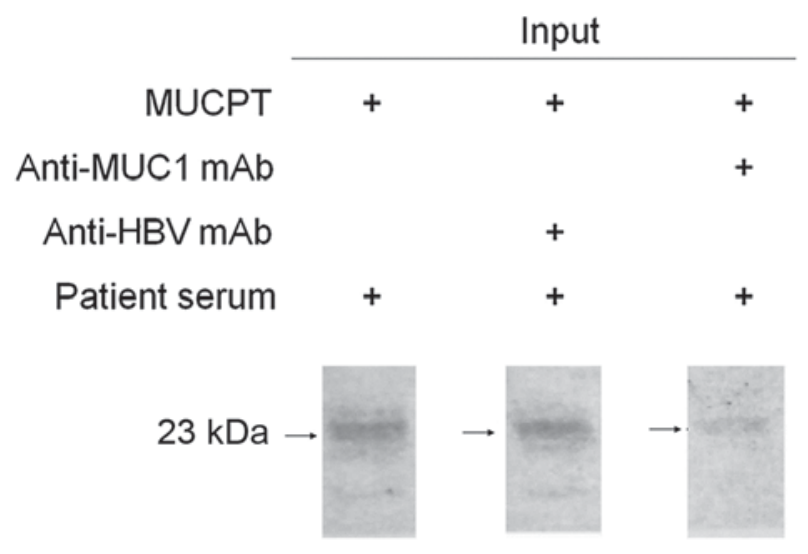

Figure 2. Western blot analysis and inhibition test with the MUC1 variable number of tandem repeats antigen. MUC1, mucin 1; MUCPT, 8R-MUCPT fusion protein; $\mathrm{HBV}$, hepatitis $\mathrm{B}$ virus; $\mathrm{mAB}$, monoclonal antibody.

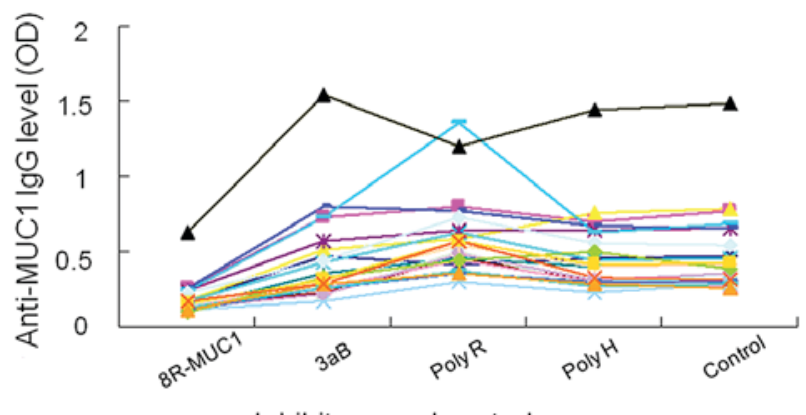

Inhibitors and control serum

Figure 3. Enzyme-linked immunosorbent assay inhibition test with the MUC1 variable number of tandem repeats antigen. Each line indicates a different sample. MUC1, mucin 1; OD, optical density.

combining ELISA showed that the AIs of anti-MUC1 IgG in stage IV and early-stage breast cancer were $47.13 \pm 11.45$ and $47.53 \pm 16.10 \%$, respectively, with no significant difference between the two groups ( $t$-test, $\mathrm{P}=0.873$ ).

\section{Discussion}

Previous studies in patients with early-stage breast cancer and other malignant tumors have found that there is a negative correlation between circulating MUC1 antigen and anti-MUC1 antibody, which indicates the formation of MUC1-CIC or the binding of anti-MUC1 antibody to MUC1 antigen in serum (19-21). In early-stage breast cancer, higher levels of MUC1-CIC are found, compared with levels at advanced stages of the disease. The levels of MUC1 are low, and marginally higher values of free anti-MUC1 antibodies are found. By contrast, patients with stage IV breast cancer present with low MUC1-CIC, but increased anti-MUC1 antibody and MUC1 antigen positivity, with high positive rates of anti-MUC1 antibody and MUC1 antigen in sera $(6,19,22)$. This indicates that anti-MUC1 antibodies are of low affinity. In the present study, the number of serum samples detected and analyzed from patients with stage IV breast cancer was higher, compared with that in a previous study (19), and were compared with the data from early-stage breast cancer.
The results showed that there was formation of MUC1-CIC or binding of anti-MUC1 antibody to MUC1 antigen in serum samples from stage IV and early-stage breast cancer. According to the previous study (19), at least one in six patients with stage IV breast cancer showed higher serum levels of MUC1, and increased free $\operatorname{IgM}, \operatorname{IgG}$ and MUC1-CIC. In addition, Nakamura et al (18) reported that 27 patients with stage III or IV colorectal cancer were detected with serum MUC1 antigen or anti-MUC1 antibody, and 2 of these patients were positive for serum MUC1 antigen and increased anti-MUC1 antibodies, including one with values marginally above the cut-off.

In order to confirm the interaction between the serum anti-MUC1 antibody and MUC1 antigen in stage IV breast cancer, and to examine differences in IgG affinity between serum samples from stage IV and early-stage breast cancer, the present study performed western blot analysis, an inhibition test and an ELISA inhibition test. The results of the western blot analysis and inhibition test showed that serum anti-MUC1 antibody in stage IV breast cancer was bound to MUC1 antigen. In the ELISA inhibition test, the inhibitors respectively represented an unpurified component of 8R-MUCPT protein, synthetic peptides of 8 lysine and a poly-hist tail, which were designed to prevent the effect of irrelevant antibodies in detecting anti-MUC1 antibody. The results showed that only $8 \mathrm{R}-\mathrm{MUCPT}$ inhibited the reaction, which confirmed that the serum MUC1 antigen or tandem repeat sequence of MUC1 reacted with anti-MUC1 antibody in the serum of patients with stage IV and early-stage breast cancer. A total of 11 serum samples from IV stage breast cancer and 11 from early-stage breast cancer were assessed. No statistically significant difference was found between the two groups ( $t$-test, $\mathrm{P}=0.778$ ). MUC1-IgG affinity can affect the binding of MUC1 antigen with anti-MUC1 antibody, thus affecting the inhibition ratio. The results of the present study suggested that there was no significant difference in MUC1-IgG affinity between stage IV and early-stage breast cancer.

To further examine the difference in IgG affinity between serum samples from stage IV and early-stage breast cancer, all serum samples selected were analyzed using a urea degradation combining ELISA. This assay is a common method to detect the affinity of an antibody $(23,24)$ and also enables the examination of a larger sample size. The results showed no differences between stage IV and early-stage breast cancer in the affinity of anti-MUC1 $\operatorname{IgG}(t$-test, $\mathrm{P}=0.873$ ).

Usually, in addition to the affinity of an antibody, the ratio between the antigen and antibody, the concentration of the antigen and/or antibody, and other factors can have an effect on the binding of antigen and antibody or the formation of the antigen-antibody complex. In stage IV breast cancer, there was increased serum MUC1 antigen (25), therefore, the concentration of MUC1 antigen requires consideration if binding is decreased or MUC1-CIC is low.

In conclusion, circulating anti-MUC1 antibody was found to bind serum MUC1 antigen in stage IV breast cancer, however, the compatibility of anti-MUC1 antibody and MUC1 antigen may be low. No significant difference was found in the affinity of anti-MUC1 antibody between stage IV breast cancer and early-stage breast cancer. In the future, the low 
compatibility of anti-MUC1 antibody and MUC1 antigen in stage IV breast cancer requires further investigation.

\section{Acknowledgements}

This study was supported by the Research Foundation of the Science and Technology Department of Jilin Province, China (grant no. 20120714).

\section{References}

1. Sinn BV, von Minckwitz G, Denkert C, Eidtmann H, Darb-Esfahani S, Tesch H, Kronenwett R, Hoffmann G, Belau A, Thommsen $\mathrm{C}$, et al: Evaluation of Mucin-1 protein and mRNA expression as prognostic and predictive markers after neoadjuvan chemotherapy for breast cancer. Ann Oncol 24: 2316-2324, 2013.

2. Haddon L and Hugh J: MUC1-mediated motility in breast cancer: A review highlighting the role of the MUC1/ICAM-1/Src signaling triad. Clin Exp Metastasis 32: 393-403, 2015.

3. Carmon L, Avivi I, Kovjazin R, Zuckerman T, Dray L, Gatt ME, Or R and Shapira MY: Phase I/II study exploring ImMucin, a pan-major histocompatibility complex, anti-MUC1 signal peptide vaccine, in multiple myeloma patients. Br J Haematol 169: 44-56, 2015.

4. Kovjazin R, Horn G, Smorodinsky NI, Shapira MY and Carmon L: Cell surface-associated anti-MUC1-derived signal peptide antibodies: Implications for cancer diagnostics and therapy. PLoS One 9: e85400, 2014.

5. Mohit E, Hashemi A and Allahyari M: Breast cancer immunotherapy: Monoclonal antibodies and peptide-based vaccines. Expert Rev Clin Immunol 10: 927-961, 2014.

6. von Mensdorff-Pouilly S, Verstraeten AA, Kenemans P, Snijdewint FG, Kok A, Van Kamp GJ, Paul MA, Van Diest PJ, Meijer S and Hilgers J: Survival in early breast cancer patients is favorably influenced by a humoral immune response to polymorphic epithelial mucin. J Clin Oncol 18: 574-583, 2000.

7. Hamanaka Y, Suehiro Y, Fukui M, Shikichi K, Imai K and Hinoda Y: Circulating anti-MUC1 IgG antibodies as a favorable prognostic factor for pancreatic cancer. Int J Cancer 103: 97-100, 2003.

8. Reddish M, MacLean GD, Koganty RR, Kan-Mitchell J, Jones V, Mitchell MS and Longenecker BM: Anti-MUC1 class I restricted CTLs in metastatic breast cancer patients immunized with a synthetic MUC1 peptide. Int J Cancer 76: 817-823, 1998.

9. Tang CK, Katsara M and Apostolopoulos V: Strategies used for MUC1 immunotherapy: Human clinical studies. Expert Rev Vaccines 7: 963-975, 2008.

10. von Mensdorff-Pouilly S, Moreno M and Verheijen RH: Natural and induced humoral responses to MUC1. Cancers (Basel) 3: 3073-3103, 2011.

11. Pericleous LM, Richards J, Epenetos AA, Courtenay-Luck N and Deonarain MP: Characterisation and internalisation of recombinant humanized HMFG-1 antibodies against MUC1. Br J Cancer 93: 1257-1266, 2005.
12. Thie H, Toleikis $\mathrm{L}$, Li J, von Wasielewski R, Bastert G, Schirrmann T, Esteves IT, Behrens CK, Fournes B, Fournier N, et al: Rise and fall of an anti-MUC1 specific antibody. PLoS One 6: e15921, 2011.

13. Pastan I, Hassan R, FitzGerald DJ and Kreitman RJ: Immunotoxin treatment of cancer. Annu Rev Med 58: 221-237, 2007.

14. Teicher BA: Antibody-drug conjugate targets. Curr Cancer Drug Targets 9: 982-1004, 2009.

15. Edge SB and Compton CC: The American joint committee on cancer: the 7th edition of the AJCC cancer staging manual and the future of TNM. Ann Surg Oncol 17: 1471-1474, 2010.

16. Tang Y, Wang L, Zhang P, Wei H, Gao R, Liu X, Yu Y and Wang L: Detection of circulating anti-mucin 1 (MUC1) antibodies in breast tumor patients by indirect enzyme-linked immunosorbent assay using a recombinant MUC1 protein containing six tandem repeats and expressed in Escherichia coli. Clin Vaccine Immunol 17: 1903-1908, 2010.

17. Klee GG and Schreiber WE: MUC1 gene-derived glycoprotein assays for monitoring breast cancer (CA 15-3, CA 27.29, BR): Are they measuring the same antigen? Arch Pathol Lab Med 128: 1131-1135, 2004.

18. Nakamura H, Hinoda Y, Nakagawa N, Makiguchi Y, Itoh F, Endo T and Imai K: Detection of circulating anti-MUC1 mucin core protein antibodies in patients with colorectal cancer. J Gastroenterol 33: 354-361, 1998.

19. Croce MV, Isla-Larrain MT, Demichelis SO, Gori JR, Price MR and Segal-Eiras A: Tissue and serum MUC1 mucin detection in breast cancer patients. Breast Cancer Res Trea 81: 195-207, 2003.

20. Richards ER, Devine PL, Quin RJ, Fontenot JD, Ward BG and McGuckin MA: Antibodies reactive with the protein core of MUC1 mucin are present in ovarian cancer patients and healthy women. Cancer Immunol Immunother 46: 245-252, 1998

21. Treon SP, Maimonis P, Bua D, Young G, Raje N, Mollick J, Chauhan D, Tai YT, Hideshima T, Shima Y, et al: Elevated soluble MUC1 levels and decreased anti-MUC1 antibody levels in patients with multiple myeloma. Blood 96: 3147-3153, 2000.

22. von Mensdorff-Pouilly S, Gourevitch MM, Kenemans P, Verstraeten AA, Litvinov SV, van Kamp GJ, Meijer S, Vermorken $\mathrm{J}$ and Hilgers $\mathrm{J}$ : Humoral immune response to polymorphic epithelial mucin (MUC1) in patients with benign and malignant breast tumors. Eur J Cancer 32: 1325-1331, 1996.

23. Revello MG, Gorini G and Gerna G: Clinical evaluation of a chemiluminescence immunoassay for determination of immunoglobulin g avidity to human cytomegalovirus. Clin Diagn Lab Immunol 11: 801-805, 2004.

24. Schoenardie ER, Scaini CJ, Avila LF, Sperotto RL, Borsuk S, Felicetti CD, Pepe M and Berne ME: Determination of IgG avidity in BALB/c mice experimentally infected with Toxocara canis. Rev Bras Parasitol Vet 23: 403-406, 2014.

25. Moazzezy N, Farahany TZ, Oloomi M and Bouzari S: Relationship between preoperative serum CA 15-3 and CEA levels and clinicopathological parameters in breast cancer. Asian Pac J Cancer Prev 15: 1685-1688, 2014. 